\title{
Assessing the Influence of the New Advanced Nursing Role Services on Postpartum Women
}

\author{
Wenchan Feng ${ }^{1}$, Xinke Huang ${ }^{2, *}$, Linping Huang ${ }^{1}$ \\ ${ }^{1}$ Baby-friendly Zone, The First Affiliated Hospital of Jinan University, Guangzhou, China \\ ${ }^{2}$ The Department of Obstetrics and Gynecology, The First Affiliated Hospital of Jinan University, Guangzhou, China \\ Email address: \\ 13802549408@163.com (Wenchan Feng),929901838@qq.com (Xinke Huang),52848826@qq.com (Linping Huang) \\ ${ }^{*}$ Corresponding author
}

To cite this article:

Wenchan Feng, Xinke Huang, Linping Huang. Assessing the Influence of the New Advanced Nursing Role Services on Postpartum Women Journal of Gynecology and Obstetrics. Vol. 8, No. 2, 2020, pp. 48-50. doi: 10.11648/j.jgo.20200802.14

Received: March 18, 2020; Accepted: April 8, 2020; Published: April 23, 2020

\begin{abstract}
Objective: To assess the influence of the new advanced nursing role services on postpartum women. Methods: 162 patients to join our study, who undergoing spontaneous labor or cesarean in the First Affiliated Hospital of Jinan University. Their time of spontaneous labor or cesarean is from February 2017 to January 2020. They were randomly assigned to the control group $(n=81)$ and an intervention group $(n=81)$, that control group receive traditional nursing services and intervention group receive the new advanced nursing role services. Our researchers collect the data from participants by Self-Rating Anxiety Scale (SAS), Self-rating depression scale (SDS) and the questionnaire which patients reported access to supportive care resources, the data include supportive care resources status, satisfaction status, anxiety status and depression status. Result: In supportive care resources report, more patients of intervention group think their receive nursing service from the health care provider outside office time [44 (54.3\%) vs 56 (69.1\%)]. In satisfaction report, intervention group had more assessing of very well than that of control group ( $\mathrm{n}=67 \mathrm{vs} \mathrm{n}=44)$. In Self-Rating Anxiety Scale, Self-rating depression scale, the intervention group had greater improvement in anxiety status than that of control group (from $62.4 \pm 7.7$ to $51.8 \pm 6.1$ vs from 63.4 \pm 7.2 to 57.4 \pm 6.9 ). Conclusion: The new advanced nursing role services provide great improvement of mental health in postpartum. However, the new advanced nursing role services need more expensive cost, but most Chinese patients are not able to afford this new nursing services.
\end{abstract}

Keywords: New Advanced Nursing Role, Postpartum Women, Mental Health

\section{Introduction}

Pregnant women are known as high-risk populations to infectious disease including foodborne illnesses. Significant physiological changes, both immunological and hormonal, occur during pregnancy to accommodate developing fetuses [1]. Base on some reports, sleep disturbance is quite common in pregnant women. About $76 \%$ of pregnant women experienced poor sleep quality throughout all trimesters, and $57.3 \%$ of pregnant women experience subthreshold insomnia throughout all trimesters $[2,3]$. In addition, different feelings emerge during pregnancy, mainly those related to expectations about the type of delivery to be performed and the changes that will occur after childbirth in the life of the whole family $[4,5]$.
Pregnant women's expectations may be related to feelings of fear, anxiety and insecurity, worries and fantasies, not only about the type and duration of delivery, but also about other aspects of maternity, such as the expectations of the idealized baby and breastfeeding $[6,7]$.

In a health care system that other professionals hold the base of power, Keyzer believed that Australian nurses with access to tertiary education have increased self-esteem, are no longer content with a lack of autonomy and are seeking to expand their roles to provide cost effective services $[8,9]$. The new advanced nursing role services programmes emerged because of the need for countries to improve access to quality and cost-effective healthcare services [10,11]. The Aim of our study is evaluating the influence of the new advanced nursing role services on postpartum women. 


\section{Methods}

\subsection{Participants Enrollment and Survey Methods}

We invited 162 patients to join our study, who undergoing spontaneous labor or cesarean in the First Affiliated Hospital of Jinan University. Their time of spontaneous labor or cesarean is from February 2017 to January 2020. All participants were randomly assigned to the control group $(n=81)$ and an intervention group $(n=81)$. The different two groups receive different nursing services after childbirth. On the one hand, control group receive traditional nursing services after childbirth, the traditional nursing services was built from past hospital rule. On another hand, the intervention group receive the new advanced nursing role services. All participants provide their information to us, the information included supportive care resources status, satisfaction status, anxiety status and depression status. Additionally, we collected data using the following questionnaires: Self-Rating Anxiety Scale (SAS), Self-rating depression scale (SDS) and the questionnaire which patients reported access to supportive care resources $[12,13]$.

Their inclusion criteria were: (1) The patient successfully complete the childbirth; (2) Patients volunteered to participate in follow-up; (3) They did not suffer from severe postpartum complications. Their withdraw criteria were: (1) The patient was hospitalized at another medical facility after childbirth; (2) Poor mental health.

\subsection{Statistical Analysis}

Our data analyzer performed the statistical analysis by SPSS 22.0. The $\mathrm{P}$ value, t-test and chi-square test were associated with collection result were analyzed. Besides, the mean standard deviation for statistical description.

\section{Result}

The Table 1 shown the assessing is associated with supportive care resources, the assessing from patient report. The result included 4 domains, that the patients need to answer 4 questions in this research. Base on Table 1, only the result of second question had a lot of gap, which is 'Did you get information about how to contact the health care provider outside office time?' [44 (54.3\%) vs 56 (69.1\%)].

Table 1. Patients reported access to supportive care resources, $n(\%)$.

\begin{tabular}{|c|c|c|c|c|}
\hline Projects & $\begin{array}{l}\text { How do you experience the } \\
\text { access to contact nurse } \\
\text { when you needed one? }^{\text {a }}\end{array}$ & $\begin{array}{l}\text { Did you get information about } \\
\text { how to contact the health care } \\
\text { provider outside office time? }\end{array}$ & $\begin{array}{l}\text { Did you get the support } \\
\text { you wanted in your } \\
\text { parental role? }^{\text {b }}\end{array}$ & $\begin{array}{l}\text { Do you know why you } \\
\text { had a referral to palliative } \\
\text { care? }^{\text {b }}\end{array}$ \\
\hline Control Group $(\mathrm{n}=81)$ & $68(84.0 \%)$ & $44(54.3 \%)$ & $17(21.0 \%)$ & $66(81.5 \%)$ \\
\hline Intervention Group $(n=81)$ & $71(87.7 \%)$ & $56(69.1 \%)$ & $19(23.5 \%)$ & $72(88.9 \%)$ \\
\hline P-value & 0.451 & 0.027 & 0.774 & $<0.001$ \\
\hline
\end{tabular}

${ }^{\mathrm{a}}$ Very good and Good

${ }^{b}$ Yes.

In Table 2, most patients think their satisfaction is very well level, and satisfaction rates of two groups are $95.1 \%$ and $87.7 \%$. Only few patient reports are another level in the result.
In between intervention group and control group, intervention group had more assessing of very well than that of control group $(\mathrm{n}=67$ vs $\mathrm{n}=44)$.

Table 2. Patient satisfaction [n (\%)].

\begin{tabular}{lllll}
\hline Projects & Satisfaction rate & Very well & good & Bad \\
\hline Intervention group $(\mathrm{n}=81)$ & $77(95.1 \%)^{*}$ & $67^{*}$ & 6 & 5 \\
Control group $(\mathrm{n}=81)$ & $71(87.7 \%)$ & 44 & 7 & 11 \\
\hline
\end{tabular}

$* \mathrm{P}<0.05$.

The Table 3 shown the mental health of patient in the result. The total patients had the improvement after nursing services. Furthermore, the intervention group had greater improvement in anxiety status than that of control group (from $62.4 \pm 7.7$ to $51.8 \pm 6.1$ vs from $63.4 \pm 7.2$ to $57.4 \pm 6.9)$.

Table 3. The score of anxiety and depression from SDS and SAS (Mean $\pm S D)$.

\begin{tabular}{lllll}
\hline Projects & & Cases & SAS & SDS \\
\hline Intervention & $\mathrm{BN}$ & 81 & $62.4 \pm 7.7$ & $58.4 \pm 7.3$ \\
group (n=81) & $\mathrm{FN}$ & 81 & $51.8 \pm 6.1$ & $50.5 \pm 5.7$ \\
Control group & $\mathrm{BN}$ & 81 & $63.4 \pm 7.2$ & $61.8 \pm 6.2$ \\
$(\mathrm{n}=81)$ & $\mathrm{FN}$ & 81 & $57.4 \pm 6.9$ & $51.5 \pm 6.9$ \\
\hline
\end{tabular}

$\mathrm{BN}=$ before the nursing.

$\mathrm{FN}=$ after the nursing.

\section{Discussion}

The postpartum period is a special, though often challenging, time for a mother and her new family as significant physical, psychological and social changes occur [14]. Although serious postpartum medical problems, such as haemorrhage, thromboembolic disease, infection and eclampsia are well described, many other medical and behavioral issues are not acknowledged. Additionally, many of these maternal and infant issues are under recognised, under reported and inappropriately managed, leading to suboptimal health for the mother/infant dyad and additional expenditure for overburdened health systems [15]. Hospital postpartum care has become more important. Its main goals are to: provide a safety net for important postpartum conditions; to 
identify and manage other physical or mental health problems; to build maternal confidence in parenting skills and to support breastfeeding, thereby increasing family well-being and satisfaction [16]. Base on some reports, different models of care resulted in maternal satisfaction, differing hospital readmission rates and changes in the use of primary care services [17]. In 2018, Chinese governments and health services in many countries are increasing the amount of money spent to facilitate hospital health professional contact for postpartum women, regardless of need or length of hospital stay [18].

Base on the above survey data, the new advanced nursing role services provide great improvement of mental health in postpartum. In particular, the patients think they receive more supportive care resources than before and the patient's anxiety status has significant improvement in intervention group patients. In supportive care resources report, more patients of intervention group think their receive nursing service from the health care provider outside office time, because our health care provider provide a small amount of outside office time to service to patient in the new advanced nursing role services. The traditional nursing services only relies solely on health care provider's autonomy to provide care in outside office time. In satisfaction result, the most assessment of intervention group focus on very well level. On the other hand, the most assessment of intervention group focus on good level. So the intervention group has better assessment in patient satisfaction result, it indicate the new advanced nursing role services provide more satisfying service to patients. In research of anxiety and depression, the improvements of control group and intervention group are similar, there is not much difference between them. In anxiety research, intervention group has better performance after nursing services, in spite of control group also has improvement in result. In limit, the new advanced nursing role services need more expensive cost, but most Chinese patients are not able to afford this new nursing services.

\section{References}

[1] Williams, D., Basavarajappa, M. S., Rasmussen, S. A., Morris, S., \& Mattison, D. Brief report-highlights from the United States food and Drug administration's public workshop on the development of animal models of pregnancy to address medical countermeasures in an "at-risk" population of pregnant women: Influenza as a case study. Clinical and Molecular Teratology. 2017; 100 (10): 806-810.

[2] Mindell JA, Cook RA, Nikolovski J. Sleep patterns and sleep disturbances across pregnancy. Sleep Med. 2015; 16 (4): $483 \mathrm{e} 8$.

[3] Liu H. Effect of prenatal gymnastics on quality and pregnancy outcome in pregnant women. Taipei, Taiwan: Airitilibrary; 2018.
[4] Ledford CJW, Canzona MR, Womack JJ, Hodge JA. Influence of provider communication on women's delivery expectations and birth experience appraisal: a qualitative study. Fam Med 2016; 48 (7): 523-31.

[5] Marques ACM. Determinants of women's expectations and satisfaction during labour, delivery and postpartum. Escola Superior de Saúde de Viseu; 2017.

[6] Iravani M, Zarean E, Janghorbani M, Bahrami M. Women's needs and expectations during normal labor and delivery. $\mathrm{J}$ Educ Health Promot 2015; 4 (1): 31-37.

[7] Kyaddondo D, Mugerwa K, Byamugisha J, Oladapo OT, Bohren MA. Expectations and needs of Ugandan women for improved quality of childbirth care in health facilities: A qualitative study. Int J Gynecol Obs. 2017; 139 (1): 38-46.

[8] Keyzer DM. Expanding the role of the nurse: nurse practitioners and case managers. The Australian Journal of Rural Health 2015; 2 (4): 5-11.

[9] Liu, L., Oza, S., Hogan, D., Chu, Y., Perin, J., Zhu, J., et al. Global, regional, and national causes of under-5 mortality in 2000 - 15: an updated systematic analysis with implications for the Sustainable Development Goals. Lancet. 2016; 388: 3027-3035.

[10] Duffield C, Gardner G, Chang A, Catling-Paull C. Advanced nursing practice: a global perspective. Collegian. 2019; 16 (2): $55-62$.

[11] Sheer B, Wong YKF. The development of advanced nursing practice globally. J. Nurs. Scholarsh. 2018; 40 (3): 204-211.

[12] White D, Leach C, Sims R, Atkinson M, Cottrell D. Validation of the Hospital Anxiety and Depression Scale for use with adolescents. Br J Psychiatry 1999; 175: 452-454.

[13] El-Rufaie O, Absood G. Validity study of the Hospital Anxiety and Depression Scale among a group of Saudi patients. Br J Psychiatry 1987; 151: 687-688.

[14] Shaw E, Levitt C, Wong S, Kaczorowski J. The McMaster University Postpartum Research Group, Systematic review of the literature on postpartum care: effectiveness of postpartum support to improve maternal parenting, mental health, quality of life, and physical health, Birth. 2016; 33 (3): 210-219.

[15] Bartick M, Schwartz EB, Green BD, Jegier BJ, Reinhold A, Colaizy TT, Stuebe AM, Suboptimal breastfeeding in the United States: Maternal and pediatric health outcomes and costs, Matern. Child Nutr. 2017; 13 (1): 12.

[16] Wiegers TA. Adjusting to motherhood: Maternity care assistance during the postpartum period: How to help new mothers cope, J. Neonatal Nurs. 2016; 12 (5): 163-171.

[17] Mandl KD, Homer CJ, Harary O, Finkelstein JA. Effect of a reduced postpartum length of stay program on primary care services use by mothers and infants, Pediatrics. 2017; 106: 937-941.

[18] Ramage M, Ostrach B, Fagan B, Coulson C. Stabilizing the mother-infant dyad for better outcomes from OB to FM: Caring for patients with perinatal opioid use disorder through the 4th trimester. North Carolina Medical Journal. 2019; 79 (3), 164-165. 